\title{
DIVERSIDAD SEXUAL Y ENVEJECIMIENTO. LOS CURSOS DE VIDA DE LA POBLACIÓN LGBT ARGENTINA
}

Fernando Rada Schultze ${ }^{1}$

\section{Introducción}

El objetivo del presente artículo es conocer los modos de envejecer y vejez que han desarrollado los varones gays y las mujeres lesbianas y trans de la Argentina. Para esto se propone un análisis sobre las características de esta población en las principales ciudades de la Argentina a fin de lograr diseñar una tipología de sus trayectorias de vida y vejeces. Asimismo, estos esbozos de cursos de vida de las personas mayores LGBT han sido construidos en base a hitos significativos considerados por ellos y ellas como puntos inflexión subjetivos en sus biografías. Por otro lado, a pesar de que este artículo ha sido elaborado en base a dos amplios campos de trabajo de las ciencias sociales -tales como el envejecimiento y la diversidad sexual-, debe señalarse que el enfoque que primará a lo largo de estas líneas será el de la sociología del envejecimiento, echando luz sobre la implicancia de la diversidad en el transcurso de la vida. Desde este punto de vista, deben señalarse tres axiomas que guiarán el presente trabajo.

En primer lugar debe destacarse que si bien a lo largo de la historia han existido personas denominadas viejas por sus comunidades, lo sociológicamente significativo de los tiempos que corren es que quienes ahora han envejecido son las propias sociedades. En efecto, las poblaciones viejas se han convertido en un grupo de peso para el entramado social, metamorfoseando las estructuras poblacionales. Al mismo tiempo, este creciente índice de personas añosas arroja nuevos cuestionamientos que convierten a este proceso en un amplio y fértil terreno de trabajo para la sociología. En efecto, el envejecimiento de la población no sólo nos invita a un profundo análisis, sino que también abre nuevos interrogantes y retos en diversas áreas de la sociedad. Entre ellas, el fenómeno presente de reconfiguración poblacional nos impele a reflexionar en torno a los modos en los que la agenda estatal se compone: a qué población atañen las políticas diseñadas, cuál es su cobertura, de qué modo consideran a la población adulta mayor y sus características, y cómo se planifican y ejecutan

\footnotetext{
${ }^{1}$ Universidad de Buenos Aires.
} 
acorde a los tiempos actuales, entre otras, ya que la gestión de una política que desconoce a las particularidades de sus habitantes estará condenada al fracaso (Rada Schultze, 2016a).

A su vez, derivado de lo anterior, una segunda premisa para reflexionar sobre estas cuestiones es que el envejecimiento de nuestras comunidades se nos presenta como una tendencia regularizada, normalizada y cristalizada plausible de indagación y con un marcado impacto sobre la urdimbre social. Así, haciendo propia la conceptualización durkhemiana, podremos decir que el fenómeno del envejecimiento se nos presenta como un hecho social en sí mismo.

Empero, no es sólo su regularidad lo que caracteriza al envejecimiento como hecho social. ${ }^{2}$ Otra de las particularidades señaladas por el sociólogo francés ha sido que los hechos sociales no tienen al individuo como sustrato, sino a la sociedad (Durkheim, 2005: 138-139). Lo cual nos conduce a pensar que el proceso de envejecimiento actual, como así también la vejez, sus causas y rasgos distintivos, son de carácter social. En síntesis, también debemos considerar a la vejez como un constructo social y no como un mero proceso biológico. Es en esa línea que el tercer axioma que orientará este artículo versa sobre la diversidad en un sentido amplio.

Quienes desde la sociología estudiamos el fenómeno de la vejez, sostenemos que ella es la derivación de un proceso dinámico y diferencial llevado adelante en el transcurso de nuestras biografías; a saber, el envejecimiento. Desde ese enfoque, en nuestros cursos de vida atravesamos un abanico de episodios que impactan sobre nuestras trayectorias condicionando los modos de envejecer y, por ende, la vejez. Es así que el envejecimiento será aquí entendido como un proceso plagado de dinamismo y la vejez como corolario de aquellos sucesos surcados, tanto positivos como negativos, y de las vivencias acumuladas en nuestros cursos de vida. Asimismo, hablar de un sinfín de experiencias acopiadas a lo largo de nuestras biografías y la valorización que de ellas hacemos, sean estas de aprobación o rechazo, implica hablar de la subjetividad y el sentido que atribuimos a estos eventos. Esto nos conduce a hablar de los múltiples puntos de inflexión significativos.

\footnotetext{
${ }^{2}$ Ampliando el uso de la terminología durkhemiana sobre el proceso de envejecimiento poblacional actual, otra de las características de su conceptualización que podríamos emplear es la del carácter coercitivo de los hechos sociales. La normatividad de estos y su imposición sobre las personas se hace presente en una cuestión básica de la demografía actual: las sociedades aspiran a que sus habitantes vivan cada día más, al tiempo que la eutanasia y la decisión sobre la propia vida y muerte, salvo escasas excepciones, sigue siendo un tema tabú. En efecto, son de público conocimiento una serie de vaticinios que pronostican la extensión de la esperanza de vida cercana a los 120 años para mitad de siglo (Magnus, 2011). Sin embargo, esto abrirá nuevos y profundos interrogantes tanto sobre el sentido de las edades como el de la ampliación de la expectativa de vida.
} 
Como señalan Oddone y Aguirre (2005), entre las variadas dimensiones que impactan a lo largo de nuestros cursos de vida, encontramos multiplicidad de variables de carácter económico, étnico, cultural, genérico-sexual, religioso, entre otras, del mismo modo que la combinación de ellas. De esa forma, la diferenciación que se presenta en nuestras biografías nos empuja a dar cuenta de las vejeces y los envejecimientos en plural, no buscando circunscribir lo indagado a prenociones estáticas basadas en nuestros preconceptos del sentido común de lo considerado viejo o vieja o una persona LGBT. Menos aún de una persona mayor trans, lesbiana o gay (Rada Schultze, 2018a: 111-112). Así es que, como ha destacado Bauman (2005), el enmarañado y diverso tejido social actual nos obliga a los investigadores e investigadoras en ciencias sociales a buscar dilucidar y explicar su sentido y no ya a juzgarlo como en antaño.

De este modo, la intención de dar cuenta de las trayectorias vitales, mediante los testimonios y memorias de las personas mayores, busca como meta poner de manifiesto los puntos de inflexión subjetivos que a su entender habrían impactado en sus cursos de vida. A su vez, esta tarea allanará el camino hacia la comprensión de los múltiples modos de envejecimiento (y por ende de vejez) indagando en simultáneo los sentidos que las personas mayores LGBT atribuyen a sus vivencias pasadas considerando dichas experiencias como hitos significativos en sus biografías.

No obstante, desde nuestro acervo cultural es poco frecuente asociar a la vejez como el resultado de un proceso o una construcción sociocultural llena de diversidades. Por el contrario, desde el sentido común la vejez es considerada como una etapa estática y acabada de la vida, atribuyéndosele una inacabable variedad de desvalorizaciones que abarcan desde la decrepitud intelectual a la corporal. Este desprestigio social, que encuentra en las personas mayores su sujeto predilecto, ha sido llamado ageism desde la gerontología, el cual suele traducirse al castellano como "edadismo" o "viejismo". Quienes conceptualizaron esta situación no sólo han puesto de relieve la desvalorización social de la cual las personas ancianas son objeto, sino que también destacan los modos en los que la extrapolación de características extravagantes presentes en una pequeña porción de la población adulta mayor nos ha llevado a relacionar a la vejez con la inutilidad o la decrepitud, resumiendo en la ancianidad una fase de la vida colmada de impedimentos (Estes y Binney, 1989).

Sin embargo, la diferenciación por edad nos presenta otras distinciones. Una de ellas es que, a diferencia de lo que ocurre con otro tipo de discriminaciones (tales como la homofobia 
o la xenofobia, por mencionar algunas), la desvalorización que compete a las personas ancianas incumbirá a toda la población

Desde este punto de vida cobra importancia la proposición del Paradigma del Curso de la Vida. En consonancia con lo dicho, este enfoque teórico sostiene que a lo largo de nuestras trayectorias estamos aventurados al influjo de diferentes eventos individuales, sociales e históricos que constituyen puntos de inflexión en nuestras historias de vida (Rada Schultze, 2018b: 71-73). Estos hitos, subjetivamente significativos, operan como bisagras en el devenir de nuestros cursos vitales, proporcionando como resultado envejecimientos y vejeces diferenciales (Elder, 1998 Lalive d'Epinay y Cavalli, 2005; Lalive d'Epinay et al, 2005; Cavalli, 2007). Es por este motivo que, al tratarse de hechos significativos en sus biografías y que los entrevistados y las entrevistadas rememoran, el método biográfico y las historias de vida constituyen técnicas de recolección de la información idóneas para esta materia.

Por tal motivo, considerando a la diversidad sexual como dimensión de análisis en el proceso de envejecimiento, del mismo modo que las repercusiones sociales que implicaría el pertenecer a grupo históricamente estigmatizado, el presente artículo se abocará a dar cuenta de cuáles fueron los puntos de inflexión relevantes para las personas entrevistadas y en qué medida ellos y ellas consideran que influyeron en sus modos de envejecimientos y vejeces.

\section{Metodología y caracterización de la muestra}

Tomando en consideración que la vejez es una construcción atada a las experiencias surcadas en nuestras trayectorias vitales, y dentro de las múltiples diferenciaciones a escoger, la diversidad sexual ha sido el aspecto destacado para este artículo, sopesándolo en tanto dimensión influyente en el proceso de envejecimiento. Sin embargo, es importante poner de manifiesto que la sexualidad, como el género de las personas entrevistadas, no son per se elementos condicionantes en las formas de envejecer. Por el contrario, lo que aquí se sostendrá es que las biografías estudiadas se encuentran signadas por las coyunturas sociales y el valor que tiene para la sociedad toda el pertenecer a las llamadas minorías sexuales. De manera sintética podemos decir que no se trata de rastrear la diferenciación haciendo énfasis en la orientación sexual de la persona o su identidad de género, sino en conocer en qué medida las históricas desvalorizaciones sociales han tenido su implicancia, en tanto puntos de inflexión, en los cursos de vida de las personas mayores LGBT.

En efecto, si brevemente extendemos el análisis al conjunto de la población argentina diferenciándola por sexo, encontramos distinciones profundas no explicables sólo desde la 
composición biológica de las personas. De ese modo, a pesar de que hallamos 1,05 nacimientos de niños por cada niña, observamos además la presencia de 0,94 varones por cada mujer en el grupo comprendido entre 55 y 64 años, relación que continúa profundizándose en el intervalo siguiente. Así, en el grupo de 65 años y más encontramos 0,71 hombres por cada mujer. A lo dicho debemos anexar que la Argentina tiene una expectativa de vida de 74 años para los varones y de 80,4 años para las mujeres. ${ }^{3}$ Si a la situación de que la Argentina tiene más nacimientos de hombres pero las mujeres presentan una mayor esperanza de vida agregáramos que este segundo grupo tiende a ser estadísticamente proclive tanto a enfermedades transmisibles como no transmisibles ${ }^{4}$, deberíamos buscar las explicaciones en las formas en que las coyunturas sociales imprimen sus características sobre las personas forjando así sus cursos vitales y no el sexo en términos exclusivamente biologicistas.

De ese modo, la premisa nodal que vertebrará las siguientes líneas propone que son los contextos sociales y culturales los que marginalizan, segregan y estigmatizan determinadas cualidades o particularidades de las personas conduciendo a que esa diferenciación señalada sea un elemento constitutivo y significativo en sus cursos vitales.

Primero veamos entonces de qué manera estas diversidades se expresan en las características de la muestra estudiada.

Dado que esta investigación buscó dar cuenta de cuáles son y qué sentido las personas entrevistadas atribuyen a los puntos de inflexión en sus cursos de vida, la misma se trató de un estudio de caso cualitativo, respondiendo la muestra a criterios teóricos. Uno de estos principios fue centrar la investigación en los principales núcleos urbanos de la Argentina. De ese modo, es que en los intervalos 2009-2015 y 2016-2018 (en el marco de proyectos de investigación UBACyT, del Programa de Envejecimiento de la FLACSO y de las becas doctoral y postdoctoral del CONICET), se han desarrollado entrevistas en las principales ciudades de la Argentina $^{5}$ con la intención de elaborar un estudio comparativo entre las diversas problemáticas de las personas mayores LGBT argentinas, debido a que ninguno de

\footnotetext{
${ }^{3}$ Datos disponibles en: http://www.deis.msal.gov.ar/wp-content/uploads/2018/04/IndicadoresBasicos2017.pdf Consultado:20.11.2018

${ }^{4}$ Datos disponibles en: http://www.msal.gob.ar/ent/index.php/vigilancia/areas-de-vigilancia/mortalidad Consultado:1.12.2018

${ }^{5}$ Algunas de las ciudades donde se ha realizado el trabajo de campo han sido Bahía Blanca, Bariloche, Ciudad Autónoma Buenos Aires y conurbano bonaerense, Córdoba, Mar del Plata, Mendoza, Paraná, Puerto Madryn, Rosario, Santa Fe, Salta y Ushuaia, entre otras. Si bien las localidades escogidas varían en la cantidad de habitantes, como luego se verá, la investigación trató de dar cuenta de las diferenciaciones de regionalismos en el país, realizando las entrevistas en las principales poblaciones del norte, centro y sur del país
} 
estos grupos (tanto el colectivo LGBT como las personas mayores, al igual que la combinación de ambas dimensiones) presentan homogeneidad en su interior.

Por su parte, la decisión de realizar el estudio en ciudades de la Argentina ha respondido a dos razones. En principio se debe a que el envejecimiento es un fenómeno urbano, desarrollándose con mayor profundidad en las ciudades producto de múltiples variables tales como el aumento de la esperanza de vida, la reducción de la natalidad y procesos migratorios (Rada Schultze, 2016a). A modo de ejemplo, podemos citar la proporción de personas mayores residentes en ciudades de países desarrollados, la cual se calcula es equiparable a los grupos de menor edad. ${ }^{6}$ A su vez, como destaca Magnus (2011), se estima que en los llamados países en vía de desarrollo la población adulta mayor se incrementará por 16 hacia la mitad de siglo, constituyendo así un 25\% de la población urbana total en los países en desarrollo.

Un segundo criterio en la selección de las ciudades es que, como ha destacado Eribon (2006), las experiencias de discriminación homofóbicas vivenciadas por el colectivo en cuestión, condujeron a que ellos y ellas se vieran empujados a migrar hacia las grandes urbes buscando eludir estas situaciones como así también persiguiendo un anonimato que les permitiera desarrollar sus sociabilidades con mayor libertad.

Respecto a las características de las personas mayores entrevistadas, con excepción del grupo de mujeres trans -particularidad que luego será profundizada-, todas han sido mayores de 60 años. Asimismo, las entrevistas e historias de vida que han servido de sustento en la elaboración de las tipologías de sus cursos de vida han sido más de 100, las cuales fueron dividas entre los tres grupos indagados. En lo referido a la distribución de frecuencia y descripción de la muestra, pueden señalarse algunos datos sintéticos de la población estudiada.

En principio se deben señalar las medias de edades como así también el máximo encontrado. Para el caso de los varones gays, la misma osciló en los 65,1 años (siendo el de 75 años el mayor caso estudiado). Respecto a la media de las mujeres lesbianas y trans fueron de 68,3 años (siendo de 92 años la mayor entrevistada) y 37,9 años (con un caso de 50 años como el de mayor edad) respectivamente. Tal como se ve, entre gays y lesbianas

\footnotetext{
${ }^{6}$ Este es por ejemplo el caso de la Ciudad Autónoma de Buenos Aires, uno de los sitios escogidos para realizar la investigación. Esta ciudad presenta la estructura poblacional envejecida ya que posee un 22,8\% de personas mayores. A su vez, este porcentaje es escasamente superado por la combinación de los grupos de 0 a 19 años (24,5\%). Estos datos se encuentran disponibles en: https://www.estadisticaciudad.gob.ar/eyc/wpcontent/uploads/2015/09/ir_2015 916.pdf Consultado: 14.11.2018
} 
encontramos la misma tendencia que distingue al envejecimiento de mujeres y hombres: la supremacía de entre 3 y 6 años de las primeras por sobre los segundos (Magnus, 2011). Otro dato interesante en la composición de la muestra giró en torno al nivel educativo alcanzado, en donde se evidenció un predominio de la educación secundaria en lesbianas y gays (72,7\% y $48,4 \%$ respectivamente) y primaria en las mujeres trans (65,3\%). A la vez, un 35,5\% de los gays accedió a estudios superiores (terciarios o universitarios), mientras que en la misma categoría las lesbianas representan un $27,3 \%$ y las trans $10 \%$.

Asimismo, otra dimensión que se consideró ha sido el lugar de origen y procedencia de las personas mayores y de qué manera había influido la "salida del closet” sobre la decisión de migrar. Allí se observa un profundo rechazo por parte de las familias ante la orientación sexual o identidad de género de la persona. En el caso de quienes pudieron comentarlo a sus familias, la aceptación de estas representa en los gays y en las trans un 25\% y en las lesbianas $40 \%$.

A su vez, se evidencia la decisión del abandono de los núcleos familiares y los sitios seleccionados para los casos en los que debieron migrar ante el rechazo de sus entornos de origen. Allí se destaca el colectivo trans que en un 65\% decidieron o se vieron empujadas a abandonar sus hogares. Esa misma situación se representa en un 10\% para los gays y un 32\% para las lesbianas. Por otro lado, entre los lugares escogidos nuevamente toman importancia las grandes ciudades, en donde se destaca la Ciudad de Buenos Aires como principal destino (43,5\% de las personas que migraron la han elegido), Rosario (21,7\%) y el Gran Buenos Aires (22\%).

Esbozada esta breve representación de la muestra estudiada, echemos luz en qué modo, mediante las memorias de las personas mayores LGBT, podemos componer sus trayectorias de vida con el objetivo de elaborar una sintética tipología de sus formas de envejecimientos y vejeces.

\section{Los cursos de vida homosexuales-gays entre la invisibilidad y la hipervisibilidad}

Este primer apartado está dedicado a poner de manifiesto las características principales de los modos de envejecer que tuvieron los mayores homosexuales-gays, detallando en simultáneo las formas que su vejez adquiere. Así, mediante la reminiscencia de los actores y los testimonios recolectados, se pueden señalar una serie de tópicos que distinguen sus biografías. 
Como se habrá podido observar en el párrafo precedente, una primera dimensión a señalar es la nomenclatura escogida para denominar a este grupo. En efecto, la doble definición homosexual-gay no es producto del azar, como así tampoco una falsa dicotomía o una invención de quien escribe. Más bien se trata de una decisión que, a fin de elaborar los modos de envejecimiento y vejeces mediante la historia de vida de los entrevistados y no basándose en categorías monolíticas, surgió como emergente del trabajo de campo. Así, se prefirió dejar a los entrevistados (y a las entrevistadas en las secciones siguientes) optar por el modo de autodefinirse, centrando la atención entonces en comprender el sentido de dichas elecciones. De este modo, retomando la cita de Bauman (2005), se buscó interpretar esa realidad de sentido y no legislarla, ya que, como ya argüía Wittgenstein, "los conceptos pueden aliviar o agravar un abuso; favorecer o inhibir” (2007: 110). ${ }^{7}$

En resumen, las personas entrevistadas deben ser consideradas en tanto testigos que tienen la facultad de testimoniar sobre una realidad sin que sea menester apelar a testimoniantes; quienes deberían relatar en el lugar aquellos que no pueden hacerlo (Agamben, 1998).

De esa forma, respetando el modo en que ellos se han nombrado, encontramos diversas razones para optar por una definición u otra motivada en diferenciaciones generacionales, políticas o de clase.

Así, mientras algunos de ellos eligen la acepción "gay”, dado que según entienden la "homosexualidad” fue social e históricamente asociada a una enfermedad, otros se identifican con "homosexual”, ya que para ellos el primer concepto representa la victoria de los países desarrollados que, mediante un mercado diseñado para los grupos jóvenes y más pudientes, buscó encorsetar y compactar la disidencia sexual en identidades. Para ellos, proclamarse como "homosexuales" era al mismo tiempo resignificar y hacer propia una noción creada para ultrajarlos. Otro de los motivos radica en la cuestión de clase, la cual en los siguientes testimonios es graficada a través de vivencias personales y humoradas.

Te voy a contar un chiste para que veas.

'Un muchacho le dice a su padre:

-Papá, soy gay.

-¿Sos gay? Te voy a hacer un par de preguntas. ¿Tenés tarjetas de crédito?

-No tengo

-¿Viajás al exterior al menos una vez al año?

-No.

-¿Tenés algún ejecutivo que te mantenga?

-No.

${ }^{7}$ El subrayado pertenece al autor. 
-Entonces no sos gay. Sos un negro puto de mierda' (ríe)

Te bombardean con lo conveniente de salir del closet, con el turismo gay, con matrimonio, pero no es para todos. Yo no pude decir ‘soy gay’ en La Matanza. Acá no existe ese glamour. No es lo mismo la Capital que estar en provincia o en el interior (José, 65 años)

En otro de los testimonios también puede encontrarse cómo los entrevistados hallan en la diferencia de clase uno de los causantes a la hora de definirse y distinguirse:

Ni mis amistades ni yo éramos del 'mundillo gay'. No salía a ‘yirar' por la Avenida Santa Fe a conocer gente. Eso no era para nosotros los negros, los grasas, las locas. ¿Acaso vos pensás que todos los putos íbamos a 'desfilar' a Santa Fe? Eso pasará para vos y tu mundo de la facultad (...) [La Avenida] Santa Fe era la meca para algunos, es verdad. Pero no para todos” (Osvaldo, 67 años).

Otra característica destacable de estas trayectorias vitales ha sido la invisibilidad. La situación de no poder asumir su orientación sexual frente a sus entornos, no pudiendo atravesar una "salida del armario", los habría empujado a dejar su vida homosocial puertas adentro. Sin embargo, al mismo tiempo vemos que los entrevistados dudan de que el destape sea un horizonte deseable para todos los subgrupos sociales (considerando las diferencias de clase, generacionales, entre otras) ${ }^{8}$ que conviven en la llamada comunidad gay: "Te bombardean con lo conveniente de salir del closet (...) pero eso no es para todos (...) Acá no existe ese glamour” (José, 65 años).

Asimismo, como señalan otros trabajos, los variados contextos sociales opresivos también operaban como obstáculo hacia la vida social gay, no encontrando más que escuetas posibilidades en la noche. Así, estas vidas homosociales quedarían limitadas entre lapsos temporales que abarcarían del crepúsculo al amanecer o soterradas en las sombras de ciudades que, al desconocer las normas de sociabilidad de este grupo, los perdía de vista. En verdad, las penumbras serían durante mucho tiempo una de las pocas posibilidades de ser y hacer con las que contarían los jóvenes homosexuales del pasado (Rada Schultze, 2012:8283). De ese modo, años atrás, las sociabilidades homosexuales-gays locales eran transitadas sin grandes oportunidades sobre los espacios de socialización, lo que daba lugar, como señala Meccia (2011), a enclaves de socialización homosexual.

\footnotetext{
${ }^{8}$ Esta diferenciación al seno del colectivo no es propia de la Argentina. Como señalaron Barrett y Pollack (2005) situaciones similares ocurren en los Estados Unidos. Asimismo, estudios recientes pusieron de manifiesto la segregación existente en los colectivos norteamericanos, británicos y españoles. Disponible en: https://www.elmundo.es/f5/comparte/2017/06/27/5950fa0a46163f5d4b8b465d.html?fbclid=IwAR2tdLmtk61 N9VXlrFV5GSr9XfpllUX7LeH4fUnKA4z0BIJ7FZRbUiKI_U Consultado: 6.12.2018
} 
Por otro lado, como consecuencia de estos cursos de vida signados por la invisibilidad, un gran número de ellos permanecerían solos, aislados y vulnerables. En cierto modo, las normas sociales que los desvalorizaban y su incorporación (tanto en el sentido de aprenderlas como de hacerlas cuerpo), los llevó a desarrollar las carreras de desviados y las profecías autoconfirmatorias (Becker, 2009; Goffman, 2010), realizando muchas veces una doble vida o replegándose sobre sí mismos, como así también en reducidos grupos secundarios. ${ }^{9}$ Estos grupos, como señala Pecheny, servirían para que las personas pudieran compartir su "secreto" sin sentirse estigmatizados. En efecto, como la diversidad sexual es objeto de discriminación, estas personas podían decidir con quienes compartir su “confesión”, al tiempo que la misma forjaría una cohesión fuerte y ambivalente entre los pares que se retroalimentaría de una constante tensión entre adentro y afuera (2005: 146).

Sin embargo, es conveniente incorporar al análisis de las trayectorias de los entrevistados el trabajo de Merton (1968), ya que brinda herramientas para captar la agencia de estos mayores. Desde su propuesta, la desviación (entendida como una sobreadaptación a las pautas culturales) da elementos para estudiar las estrategias de sobrevivencia y socialización que desarrollaron los jóvenes homosexuales de antaño, las cuales les permitían entablar relaciones sexoafectivas en coyunturas profundamente perjudiciales y así esquivar el ojo vigilante y condenatorio de un sistema opresivo hacia la heterogeneidad sexual. ${ }^{10}$

Otra de las características que pueden señalarse es la "inexistencia” de mayores en el activismo político, lo cual se presenta como una regularidad y una singular paradoja en un movimiento social longevo, que en la Argentina cuenta con referentes desde finales de los años 1960. Tampoco, en estos espacios, se cuenta con áreas destinadas al trabajo con personas mayores. Así, a pesar de que los entrevistados en parte intentan encontrar las explicaciones de esta carencia en los efectos de la epidemia del VIH sucedida en los años 1980 -considerada esta pandemia por ellos un punto de inflexión que trastocaría todas las

\footnotetext{
${ }^{9}$ Trabajos recientes como el de Rada Schultze e Ingrosso (2018) han señalado que si bien con el paso del tiempo las redes de contención suelen mermar por diversos motivos (tales como el fallecimiento de las personas añosas), los y las mayores LGBT tienden a forjar nuevos lazos sociales que operan como segundas familias.

${ }^{10}$ Si bien líneas arriba hemos utilizado términos como disidencia o diversidad sexual, creemos conveniente reflexionar sobre esta cuestión. Así, de la misma forma que hemos dado inicio a este artículo mencionando lo inconveniente y contraproducente que resulta pensar en un único modelo de vejez y envejecimiento, ya que ciñe y restringe la diversidad de múltiples cursos de vida existentes, debemos también reflexionar en torno al uso de las categorías que empleamos respecto a la problemática sexual. Por esa razón a lo largo de estas páginas será común hablar de "heterogeneidad sexual" ya que la idea de diversidad propone tácitamente el "ser diverso a" presuponiendo que existe un patrón de normalidad sobre el cual medirse. Problema similar ocurre con la noción de "disidencia" la cual si bien discursivamente discute el orden social heteronormativo, presupone implícitamente una homogeneidad inexistente entre quienes conforman la base social y la cúspide que compondrían ese sistema.
} 
relaciones sociales y sexuales-, la misma deviene en un argumento insustancial a la hora de resolver la escasa participación de los mayores. En primer lugar porque correríamos la suerte de continuar injuriando a este colectivo ya que reforzaríamos el trágico y estigmatizante binomio SIDA-homosexual y, en simultáneo, a los mayores al vincularlos a la muerte.

Si bien no puede desconocerse el impacto que este virus ha tenido sobre la población en cuestión, si sostuviéramos este supuesto sólo nos daría elementos para comprender la ausencia física de los viejos. Sin embargo, esta falta no sólo es palpable en las personas o espacios destinados a atender sus demandas, sino también en la ignorancia -profundizada en los activistas más jóvenes- de las historias y memorias del movimiento LGBT en Argentina. Por lo tanto, la ausencia de viejos no tendría que ser un obstáculo en pos de conocer las diversas tradiciones e historias del colectivo LGBT. Empero, en las organizaciones LGBT argentinas suele ser inusual el ejercicio reminiscente en torno a las vivencias de los antecesores o, en palabras de Tarrow (1997), “madrugadores”: aquellos militantes del pasado que darían inicio a un proceso de protesta que hoy habilitaría la conquista de nuevos derechos, tales como el Matrimonio Igualitario (2010) o la Ley de Identidad de Género (2012). No obstante, la labor inversa produce efectos adversos y así, al borrarse a las personas mayores y sus biografías, se pierde el sentido de comunidad, debido a que la misma se gesta en el seno de una tradición y trasmisión de memorias colectivas vinculantes; la cual para el caso en cuestión se disfuma paulatinamente.

\section{I. Homofobia y discriminación etaria}

Un primer elemento que arrojaría pistas para comprender la ausencia de mayores antes anunciada, es el edadismo: estamos ante el advenimiento y la aparición pública de una generación, los jóvenes del presente -fagocitados por un avance sin precedentes de la tecnología del cual este grupo etario es nativo- en detrimento de otros: los actuales viejos o los jóvenes del ayer. Si bien el edadismo se interioriza y son los propios mayores quienes creen que no pueden aportar conocimientos o experiencias, también la discriminación etaria opera sobre los jóvenes, viendo en los viejos a un ser carente de fuerzas y facultades. En ese sentido debe decirse que el desprestigio vivido por los mayores gays toma dos formas. En primer lugar, encontramos una discriminación que reúne la cuestión sexual con la edad y que se afinca en el conjunto de la trama social. Por el contrario, la segunda ocurre en el seno del colectivo y gira exclusivamente en la cuestión etaria, manifestando una imagen de que, en palabras de un entrevistado, “el puto viejo es patético” (Arturo, 63 años). 
Si bien aquí el edadismo vincula la vejez a lo grotesco y antiestético, los entrevistados rememoran la existencia, también presente, de espacios en los que el anciano es aceptado o bien vista. Según comentan, uno de estos es el caso de las relaciones sadomasoquistas. Allí la vejez emanaría una imagen de autoridad y respeto. Otro caso es el de la figuras que no cumplen con los cánones sociales de lo estipulado bello: los “osos” y los daddys; los cuales son representados por personas añosas y corpulentas. Sin embargo, a pesar de estas excepciones, al igual que ocurre en el conjunto de la sociedad, la vejez y los sujetos que la representan, no son comúnmente apreciables para los jóvenes e incluso para los propios viejos. Empero, no debe suponerse que la discriminación etaria ha sido la mayor segregación acontecida en estos cursos de vida. Mientras la discriminación por edad sólo se presenta al evidenciarse las huellas del tiempo sobre los cuerpos envejecidos, el descrédito social homofóbico los ha acompañado de manera sistemática a lo largo de sus cursos vitales, lo cual permitirá comprender el desarrollo de las llamadas “doble vidas”; a saber, desarrollar su vida homosocial en el ámbito privado.

Sin embargo, a pesar de lo dicho, muchos de los mayores entrevistados consideran que sus sociabilidades se desarrollaban mejor en épocas anteriores, arrojando una imagen placentera de tiempos pasados, periodo de sus vidas en el que, a pesar de los existentes abusos y razias policiales, “todo era más apacible y ameno” (Juan, 69 años). En simultáneo, otros mayores destacan que en décadas pasadas habría existido una mayor integración entre clases sociales, edades y diversos grupos sexuales y que las razones de las experiencias discriminatorias deben hallarse en los modos en que cada persona desarrolla su vida diaria: "Si vos respetas, te respetan. No es necesario andar mostrándose tanto” (Raúl, 65 años). Empero, este imaginario no puede más que oponerse a los eventos relatados por otros mayores, sobre todo los de aquellos que relatan episodios de amenazas, hurtos de taxi boys o “crímenes de odio", entre otros.

\section{II. Puntos de inflexión en los cursos vitales homosexuales-gays}

Sin lugar a duda uno de los mayores hitos significativos en sus cursos vitales ha sido el descubrimiento de su orientación sexual, la cual es situada por ellos en la adolescencia o juventud. En lo que a la "salida del closet” compete, observamos que mucho de ellos no lo ha hecho y que tampoco lo ve con buenos ojos. Por el contrario, el ser socializados para el oprobio condujo a que permanecer en las sombras y el anonimato fuese una opción 
apetecible. Esto daría lugar a las llamadas “doble vida” y la censura de su vida homosocial en el ámbito público, dejándola de ese modo puertas adentro.

Si bien ellos son conscientes que las coyunturas han cambiado, el haber sido educados bajo el halo de otros marcos y representaciones sociales genera una tensión e incompatibilidad con los tiempos que corren; contexto que además no los desea ni como protagonistas ni consumidores. Así, es comprensible que gran parte de los entrevistados recuerden con nostalgia el pasado. Un pasado que los posicionó como jóvenes y como objeto de deseo. Al mismo tiempo, la escasez de un imaginario homogéneo respecto a los diferentes períodos, incita a debatir sobre el grado y la capacidad de integración de cada época.

A pesar de que la representación de los viejos pareciese manifestar la existencia de una mayor “aceptación” décadas atrás, lo mismo también es entendible desde el edadismo.

Ante la metamorfosis del escenario que los supo posicionar como protagonistas, es comprensible que los viejos perciban que algo están perdiendo. No obstante, tampoco es una labor sencilla para ellos asumirse como ancianos, ya que la vejez suele representarse como sinónimo de inutilidad. De esa forma, su agencia se centró en discutir generacionalmente la legitimidad de vivencias. Así, rememoraron con melancolía su pasado al tiempo que lo representaron como un período idílico caracterizado por una mayor solidaridad interclasista e intergeneracional.

Por otro lado, esa tensión, resultado del cambio de época y contextos, deviene en una tirantez y rechazo generacional hacia aquellos que corporizan la nueva era: los jóvenes. Teniendo en consideración esto, es comprensible que algunos de los mayores rechacen a la actual hipervisibilidad y a los activistas. Esto se debe a que se sienten impulsados a salir a la superficie cuando en décadas pasadas tuvieron que aprender a constituirse, resistir y subsistir en la oscuridad. Así, el “closet” y la "salida” no son aprehendidos y ambicionados por todos ellos como un ideal. Al mismo tiempo, el precio que sienten que deberían pagar, (a saber las consecuencias familiares) no lo consideran del todo redituable.

Para ellos, la trasmutación en sus contextos y ambientes han sido evidentes por lo cual han intentado decodificarlos y adaptarse en pos de continuar desarrollando sus vidas. Además de observar una transformación en la visibilidad y el fin de las llamadas sociabilidades en las catacumbas (Rapisardi y Modarelli, 2001), ellos también perciben un cambio en las propias reglas del juego, como así también los valores y códigos del grupo. Por ejemplo como señala uno de los entrevistados: "Para algunos el modo de levante es Internet. Para nosotros que tenemos cierta edad cuesta más adaptarse” (Mario, 65 años). Otro de los entrevistados 
profundiza sobre esta cuestión: "Muchas veces en la calle hay miradas. Se consiguen cosas, gente, pero es muy esporádico. Nadie te mira por la calle. Inclusive la gente que está en la joda, en lo nuestro, directamente no te mira. Vos lo miras y te esquiva la mirada” (Alfredo, 68 años).

En verdad el cambio de época comienza paulatinamente a socavar las raíces de la “sociedad densa” que los supo albergar años atrás, minando o cambiando al mismo tiempo el sentido de comunidad que alguna vez conocieron. Asimismo, esa idea de comunidad servía de frontera entre un "adentro" donde se podían entrelazar lazos de interdependencia y un “afuera” peligroso. Empero ese cosmos comunal sólo era viable en el contexto de un terreno definido y bajo un grupo relativamente estrecho, ya que como destaca Bauman "la aptitud esencial utilizada en su producción era la capacidad de hacer del 'otro' alguien familiar, transformarlo en una persona plenamente definida con una posición fija dentro del mundo conocido" (2005: 61).

\section{Los cursos de vida lésbicos entre el “deber ser” y el "nido vacío”}

Respecto a los cursos de vida de las lesbianas mayores, hallamos entre sus principales aspectos algunas dimensiones de correspondencia con los varones analizados líneas arriba. A pesar de que sus trayectorias también se encuentran signadas por la invisibilidad, la misma se liga a los roles de género que debieron cumplir, como por ejemplo la maternidad (Schwarz, 2008: 193-194). El deber social de tener que desempeñar las pautas culturales las condujo a que muchas de ellas fuesen madres en relaciones heterosexuales llevando adelante las normas de una sociedad patriarcal. Así, entre las entrevistadas, solamente una logró ser madre en el contexto de una pareja homoparental. Como sostiene Albarracín (2008), los preceptos sociales y la obligación de ser madre, casarse, ser ama de casa y dependiente de un varón/marido, las condujo a acallar y adormecer su sentir.

A su vez, el sentimiento de culpa y vergüenza han sido otros elementos que obstaculizaron el escape del closet. Entra las causas principales ella enumeran sus familias (tanto de origen como las que fueron construyendo) y el trabajo (donde intentaban que no se descubriera su “secreto”). La razón principal de conservar la posición laboral era que esta les brindaba un ingreso económico vital en la independencia económica de un hombre y de sus familias y, al mismo tiempo, una de las primeras posibilidades en el camino a su liberación sexual. 
Asimismo, en el marco de la obligación maternal y del formar una familia -considerado por ellas como un mandato externo y no como una elección de vida-, ellas también destacan otros dos hitos significativos que marcarían su liberación.

Por una parte, destacan el haber logrado romper con el deber ser social en su mediana edad (alrededor de sus 40 años), momento en el que redescubrirían su orientación sexual, llamado por ellas un "nuevo amanecer" en sus vidas. Por otro lado, un segundo punto de inflexión es ubicado por ellas en su vejez y consiste en el llamado "nido vacío”. Usualmente considerado un problema para las personas que lo vivencian, el "nido vacío" resultó para ellas un subterfugio ante los embates de un sistema machista. La vejez les brindaría una nueva potestad sobre sus vidas e indiferencia respecto al “qué dirán”. No obstante, si bien es cierto que tampoco lograrían revelar en público su orientación sexual, al menos conseguirían hacer propio ese deseo y no ya bajo la noción de "juego de la infancia” o "travesura juvenil” como referenciaron respecto a sus primeras y antiguas vivencias lésbicas.

Otro aspecto en el que sus cursos de vida se asemejan es en que, si bien ellas también experimentaron situaciones violentas debido a sus preferencias sexuales, algunas ven los periodos pasados con nostalgia. Del mismo modo, si bien comentan experiencias de abusos policiales o balaceras sobre lugares de ocio y esparcimiento, sostienen que la discriminación dependía de la decisión personal. Sin embargo, es una premisa básica de la sociología el hecho de que tanto las personas como sus biografías no pueden indagarse de manera atomizada o autorrealizada. Por el contrario, son los diversos contextos de socialización los que restringen o permiten ser. Inclusive, son las coyunturas y las normas sociales las que les brindaron como una única posibilidad llevar sus vidas adelante bajo el halo de la vergüenza y la sombra. Si bien esta será una forma que la autopercepción de la segregación es equiparable entre gays y lesbianas mayores, existen otros puntos de inflexión en los que sus cursos de vida se diferencian, como por ejemplo en las experiencias de discriminación.

\section{IV.I. El ser mujer lesbiana mayor como factores de una triple discriminación}

Uno de los motivos por el que la discriminación experimentada por las mayores lesbianas se diferencia se debe a tres dimensiones: la lesbofobia (la desvalorización por sus preferencias sexuales), el edadismo (motorizado por la edad) y hecho de ser mujeres en una sociedad machista. Sin embargo, más allá de las nomenclaturas, el impacto de estos desprestigios sociales se evidenció en los cursos de sus vidas conduciéndolas, como se dijo, a desarrollar los roles de género que la sociedad tenía previsto para ellas. Así, debieron 
transitar sus trayectorias ceñidas por una triple discriminación: ser mujeres, lesbianas y, ahora, viejas. Empero, primero es importante señalar las particularidades que adquiere la discriminación etaria en este grupo.

En primera instancia debe señalarse que, a pesar de que culturalmente los cuidados sobre el cuerpo y la belleza son atribuidos al género femenino (Yuni et al, 2003), las entrevistas realizadas no arrojan discursos que emparente a la vejez con lo antiestético. Tampoco ocurre con otros prejuicios como la incapacidad o la senilidad. En segundo lugar, en referencia a sus cursos vitales, hallamos que, si bien reconocen haber sentido atracción por otras mujeres durante su adolescencia, tuvieron que silenciarlo; deseo que sería camuflado o sepultado bajo el rótulo de “juego de la infancia”. De ese modo, su sentir no sólo fue categorizado como un desliz de la pubertad, sino que además fue aletargado hasta su mediana edad. A pesar de que ellas reconocen haberse sentido atraídas por otras mujeres, señalan que se vieron obligadas a decodificarlo como una travesura de la niñez; como una situación inocente e infantil.

Otro aspecto desde el cual podemos equiparar los cursos vitales de los grupos trabajados hasta ahora es en relación a las salidas del armario, debido a que tampoco ellas lo asumen como una meta deseable en sus vidas. Contrario a la idea del destape como un horizonte a alcanzar, ellas consideran que podría generarles problemas familiares y laborales, motivo por el cual también preferirían esconder su deseo. Así, durante gran parte de sus vidas omitieron, incluso muchas veces hasta para ellas mismas, su atracción por el mismo sexo. Ese silencio, sumado al influjo del “deber ser” que la sociedad les atribuyó, tuvo tal presencia que ellas sostienen haber "olvidado esa 'tendencia'”. De esta forma, tuvieron que casarse con un varón, tener hijos y criarlos y, durante muchos años, dejar en el cajón de los recuerdos aquellas aventuras infantiles. Sin embargo, si bien ese primer encuentro sería fugaz, aquella primera vivencia de deseo sería reveladora en sus biografías. Pasemos entonces a conocer de qué forma ese "nuevo despertar” o "nuevo amanecer” funciona como punto de inflexión en sus cursos de vida; como una bisagra en una nueva resignificación de aquellas "travesuras de la adolescencia”, pero esta vez como un nuevo auto-reconocimiento.

\section{II. Puntos de inflexión en los cursos de vida lésbicos}

Una vez superados los principales obstáculos, producto de la emancipación económica y familiar, gran parte de ellas en su mediana edad (en promedio a partir de los 40 años) buscaron recuperar y reparar aquel goce adormecido e inmovilizado a la par de las relaciones heterosexuales que aún mantenían. De ese modo, ellas vivirían una “vida doble”; dos vidas 
en una. El desdoble de una vida en dos momentos marcadamente diferenciables, para luego sí desarrollar una “doble vida” en los términos antes desarrollados. Sus vidas adquieren un interesante "giro de 360"” (Paulina, 92 años) en el que ellas sienten volver al mismo punto de partida, pero con las experiencias acopiadas a lo largo de sus vidas. En ese sentido, se evidencia un importante cambio y continuidad en el curso de sus vidas. Algo en sus vidas, en su identidad, ha trasmutado pero también se mantiene: “¿Es la misma Susana la de los 12 ó 13 años que la actual? ¿Soy otra? En algún punto soy la misma y en algún punto no. Algo cambió. Algo lo dejé. Pero también lo recuperé. No se perdió. Se resignificó” (Susana, 63 años).

Con el paso del tiempo, ya devenidas viejas, fomentadas por la maduración de sus descendientes y el alejamiento del hogar familiar, como así también el fallecimiento de sus familiares predecesores, sintieron que ya no sería necesario mentir u ocultarse. Así, lograrían encontrarse con ellas mismas y dar rienda suelta a su deseo. Detengámonos por un momento en el primero de estos hitos significativos de sus historias familiares señalados por ellas: el crecimiento e independencia de sus hijos e hijas.

Si bien desde la gerontología se ha acuñado el concepto del "síndrome del nido vacío" para dar cuenta del periplo anímico que padres y madres deben transitar cuando su prole decide marcharse del hogar (Raup y Myers, 1989: 180), esto no ha ocurrido con las personas entrevistadas. Por el contrario, esto ha sido revalorizado positivamente. Para ellas está muy presente la sensación de haber dejado correr gran parte de su tiempo, por lo cual aquel marco les daba la facultad de desadormecerse de esa extensa somnolencia. Este episodio en sus vidas les permitiría, además de eludir esa sensación de abotargamiento o sopor, renacer y comenzar a sentirse en complacencia con ellas mismas. En ese sentido, ellas sostienen que una vez despabiladas de aquel letargo, lograron reconciliarse con su "verdadero yo” (Claudia, 67 años), dejando así de “vivir una mentira” (Alicia, 60 años).

En efecto, la emancipación de su descendencia es un episodio sustancial en sus cursos vitales. Ellas, además de no vivenciarlo como un evento traumático o angustioso, se encuentran en esta nueva etapa de sus biografías un posibilidad para darle forma y sentido a un goce sexual e identitario postergado.

Empero, este redescubrirse no se dio de modo atomizado, sino que se fagocitó de una serie de sucesos personales y grupales. Podemos citar, en el orden temporal que se sucedieron en sus vidas, la independencia económica como otro evento destacado por ellas. En verdad, por medio del trabajo y el respectivo estipendio, ellas encontrarían una válvula de escape ente el 
avasallamiento del orden machista y patriarcal. Como destacan, la autonomía monetaria les brindaba independencia y la facultad de decidir por y sobre ellas mismas sin tener que rendir cuentas a otras personas. Se nos presenta así una ancianidad ajena a las prenociones edadistas. Se trata de una vejez empoderada en un vasto sentido que contempla desde la economía a los afectos.

En ese sentido, los hitos significativos vinculados al paso del tiempo y la edad (como por ejemplo los ya mencionados "nido vacío” o la merma en las redes sociales y de contención, como resultado del deceso de familiares), pero sobre todo la vejez, consistieron para ellas en puntos de inflexión nodales en su reconstrucción identitaria. Asimismo, ese "nuevo amanecer” (categoría empleada por ellas para denominar el hallazgo de su orientación sexual y posterior reafirmación personal), del mismo modo que las “segundas relaciones”, pero las primeras asumiéndose a sí mismas como lesbianas, operaron como bisagras en su redefinición identitaria.

\section{Los cursos de vida trans mayores y una vejez cercenada}

Al tiempo que Argentina experimenta una tendencia en alza marcadamente femenina producto de mejores condiciones de vida, existen en la sociedad grupos de riesgo para quienes la vejez es una etapa difícil de alcanzar. Tal es caso del colectivo trans, cuya esperanza de vida no supera los 45 años de edad siendo evidente la diferencia con la expectativa de vida nacional. No obstante, estos datos tan sólo son un recorte; una tipificación que poco nos dice sobre las características de las biografías, desarrollo y procesos de envejecimiento y de las vejeces como construcción social e individual atada a los múltiples fenómenos que ellas han atravesado y que han impactado a lo largo de sus vidas.

Así, ya abordados los envejecimientos gays y lésbicos, es momento de poner énfasis en los principales aspectos de los cursos vitales trans. En ese sentido, la primera dimensión a indagar sea quizá la que particulariza en mayor grado a sus envejecimientos: la vejez como un derecho negado.

La estrecha esperanza de vida de las trans, la cual según algunos trabajos oscila los 45 años (Berkins y Fernández, 2005)- encuentra sus causas en los sucesos transitados en sus cursos de vida; una serie de peripecias que se originan desde el momento que ellas asumen su identidad de género: el revelar y arrogarse esa identidad traería aparejada una gama de cambios en sus biografías que impactarían en sus modos de envejecer. 
Uno de los primeros episodios en sus trayectorias sería la reprobación familiar como resultado de la transfobia. Esto las indujo a abandonar sus hogares en su adolescencia para radicarse en las grandes ciudades argentinas, donde el anonimato y algunas limitadas opciones laborales -que a pesar de lo escueto de la oferta superaría las posibilidades en sus localidades de origen- les propiciarían acceso a la realización de su identidad y deseo.

A su vez, la indefensión que encontraron en su juventud, la ausencia de acceso a la educación y la marginación social, sólo les brindaría como posibilidad laboral la prostitución, la cual sería durante largos años, como así también para diversas generaciones, una de las escazas oportunidades con las que se toparían como medio de subsistencia ante un contexto de pobreza y marginación que marcaría todo su curso de vida.

En esa línea, ellas recuerdan el rol nodal que tendrían las “nodrizas” (forma en la que denominaron a aquellas trans mayores que alojaban y aconsejaban a las jóvenes migrantes), siendo este quizá el único ejemplo, dentro de los casos estudiados, donde podemos trazar una relación e integración entre generaciones como así también una trasmisión de saberes y legado de memorias (Rada Schultze, 2018c). Asimismo, serían las trans longevas y entendidas aquellas que en infinidad de ocasiones llevarían a cabo las cirugías clandestinas de adecuación corporal que, si bien representaba un bajo costo económico, serían abismalmente dañinas para su salud.

En efecto, la cuestión de que el cuerpo biológico, de origen, no estuviese en consonancia con el deseo identitario de las trans, coopera en el entendimiento de la necesidad de estas personas de lograr corporizar su sentir. Así, la trascendencia de conseguir armonía entre su cuerpo y su identidad autopercibida las llevaría a optar por el sendero más asequible pese a que representara una potencial amenaza.

Debe destacarse que las continuas operaciones, tanto para que la figura reflejara su anhelo y voluntad como así también para que despertara deseo en los virtuales consumidores, condujeron en un desgaste y erosión de su propia salud y cuerpo. De esa forma, la elaboración identitaria y física trans devendría en una subjetividad vulnerada y marginal, al tiempo que era la consecuencia de una posición y condición social frágil y débil: las violencias y pobrezas sempiternas a las que estarían expuestas terminarían por corporeizarse en una subjetividad doliente. En síntesis, ellas incorporarían esa vulnerabilidad; la harían parte de su cuerpo.

A pesar que desde las organizaciones políticas LGBT se ha tratado de revertir esta problemática, las políticas estatales delineadas fueron deficientes o recientes, no logrando así 
cambiar de raíz el escenario de riesgo en que habitan las trans (Rada Schultze, 2014). De ese modo, es comprensible que gran parte de los ingresos de ellas provengan todavía del trabajo sexual; espacio en el que los narcóticos, la exposición a violencias, contratiempos climáticos, entre una amplia infinidad de reveses, persisten de forma inacabable conjurándose en oposición a su bienestar (Rada Schultze, 2016b).

\section{I. Pobreza y solidaridad intergeneracional}

Contrario a lo visto en las secciones precedentes, este ha sido un colectivo en el que de manera unánime la vejez es considera en las antípodas de la belleza. Este colectivo, tal vez manteniendo alguna semejanza con lo observado en los cursos de vida gays, asocia el paso del tiempo, y el devenir mayor, con el menoscabo de la beldad.

Verdaderamente, el hecho de deber sobrevivir en base a la prostitución, como así también que sea mediante y en el cuerpo donde se forja su identidad y plasma su sentir, sobreviene en que el envejecer sea sentido por ellas como una pérdida de belleza, al igual que el sentido inverso. De esta forma, el ya no percibirse atractivas y las burlas que resultan de su apariencia física son consideras por ellas como una herida en su autoestima; como “puñaladas” (Inés, 48 años). Empero, esa no es la mayor marginación vivenciada en sus cursos vitales.

Más allá de ser segregadas por trans y mayores, debemos sumar la pobreza y el bajo nivel educativo alcanzado que, si bien no representa motivos de discriminación entre ellas, sí emerge frente a los otros grupos que componen la comunidad LGBT. A su vez, en el contexto de la trama social, las trans tampoco lograron esquivar el asedio policial que, mediante razias, edictos y contravenciones, las acosó en los ya estrechos espacios de sobrevivencia que tenían.

En lo que compete a la discriminación etaria, ellas sostienen que en su pasado había mayor respeto y reconocimiento hacia las trans mayores y su experiencia, la cual les otorgaba aquel rol de "nodrizas” para el grupo. Ese personaje de "nodriza” era considerado por las jóvenes como una persona poseedora de una experticia y saber práctico de importancia central para la supervivencia cotidiana. Ahora en cambio, ellas consideran que aquella relación intergeneracional se ha esfumado. Para las actuales mayores trans, las jóvenes son arrogantes, trazando una distinción con su conducta pasada: “Antes nosotras escuchábamos a las mayores. Te enseñaban muchas cosas. Dónde ir, dónde no ir. Cómo esconderse de la policía. Cómo esconderse en la dictadura (...) Ahora las más jovencitas se creen que se la 
saben todas” (Noelia, 50 años). Como se observa en el testimonio, las mayores actuales lamentan los tiempos que corren, al tiempo que se sentirían a gusto de poder compartir los conocimientos acopiados a lo largo de la vida en pos de que otras trans no tengan que surcar los mismos avatares.

En esa dirección, una de las problemáticas experimentadas por las trans mayores, que desean no sea repetida por sus sucesoras, es la de ejercer la prostitución como medio de subsistencia (Berkins, 2007). Adentrémonos entonces en detallar cuáles consideran han sido los principales puntos de inflexión en sus cursos vitales.

\section{II. Puntos de inflexión en los cursos de vida trans}

$\mathrm{Al}$ igual que ocurrió con las personas gays y lesbianas analizadas, las trans entrevistadas también reconocieron la adolescencia como etapa de la vida en la que descubrieron su deseo. Sin embargo, a diferencia de los grupos indagados anteriormente, el intento de plasmar su sentir identitario sobre sus jóvenes cuerpos era imposible de disimular. El cambio corporal residía en un proceso hipervisible que no podría ocultarse así se quisiera o no "salir del armario”. Por tal motivo es que muchas de ellas se vieron empujadas a dejar sus casas. De esa forma, no debieron desarrollar una “doble vida” con las características antes estudiadas. Una vez reconocida su identidad, buscarían llevarla adelante para así lograr un cuerpo en armonía con su sentir. Sin embargo, esta tarea contaría con grandes obstáculos en el curso de sus vidas dando como resultado una corta esperanza de vida, lo cual imposibilita hablar de una vejez trans en los términos conocidos. Así, a los fines analíticos de este trabajo, hemos debido considerar a la adultez mayor trans en términos relativos -ya que usualmente su expectativa de vida no supera los 45 años- y relacional -estudiando los cursos vitales de las mayores del grupo-.

En esa línea, la paupérrima calidad de vida y corta expectativa condiciona sus representaciones imposibilitándoles tener una proyección a futuro. Tal como sostienen, la soledad, la incertidumbre y las violencias que las rodean las obligaría a transitar sus vidas sin poder imaginarse un mañana. De ese modo, la vejez se les presenta a ellas como una etapa de la vida ajena en la que no pueden pensarse o realizarse.

Otro de los puntos de inflexión aludidos versa sobre su despertar sexual. La constante tensión que existía entre sus identidades autopercibidas y el cuerpo biológico, acompañada de la falta de sostén familiar, como así también el hecho de haberse criado en recovecos del país marcados por pautas sociales machistas de mayor calibre al de las ciudades, las llevó a 
abandonar sus hogares buscando un nuevo sitio donde radicarse, trabajar y realizar su deseo identitario. Sin embargo, la necesidad de conseguir un ingreso económico para subsistir y así dar comienzo a la adecuación corporal, daría origen a otros dos hitos significativos en sus trayectorias. En primer lugar, el encontrarse lejos de sus casas, sin experiencia laboral, sin educación, siendo sumamente jóvenes y parte de una cultura que no les brindaría oportunidades, hizo que la prostitución se presentase casi exclusivamente como la única posibilidad de subsistencia. En segundo término, las primeras cirugías a las que accederían serían realizadas en un marco de negligencia y clandestinidad que muchas veces impactaría en su salud. Asimismo, estos dos puntos de inflexión en sus vidas darían lugar a un tercer evento significativo: los repentinos fallecimientos y la baja expectativa de vida que impactarían en su cotidianeidad imposibilitando la posibilidad de representar o proyectar un futuro distinto.

Si bien en el 2012 la Argentina aprobó la Ley de Identidad de Género, la cual otorga el reconcomiendo de su identidad, como así también se buscó diseñar políticas sociales educativas, laborales y de salud, entre otras, es importante señalar que las mismas han sido recientes y limitadas, no logrando, por ejemplo en el caso de las propuestas laborales, desestimular la prostitución como medio de subsistencia (Rada Schultze, 2016b).

No obstante, será meta de futuros trabajos poner de manifiesto en qué forma las políticas desarrolladas, al igual que las que se susciten, transformarán los cursos de vida trans. Por tanto, ya que se trata de una comunidad vulnerada, es fundamental conocer qué políticas se llevan adelante, indagando sus características, límites y alcance. A tal fin será tarea central prestar atención a las personas beneficiaras y conocer sus necesidades. Por el contrario, desconocer las particularidades de este grupo sólo hará que se continúe reproduciendo la lógica de la vejez como un derecho negado.

En efecto, si hemos comenzado este artículo sosteniendo que la vejez es una construcción social factible de analizarse en tanto hecho social, que además este proceso se desarrolla en un contexto en el que las sociedades aspiran a que sus habitantes vivan cada día más -lo cual por ejemplo ya se evidenciaba en los Objetivos de Desarrollo del Milenio de la 55a Asamblea General de la Organización de las Naciones Unidas o en los pilares del Horizonte 2020 de la Comunidad Europea-, al tiempo que la muerte y la decisión sobre la propia vida (como por ejemplo la eutanasia) continúan siendo temas tabú (Pellissier, 2013), no podemos más que sostener que la situación particular de este colectivo, su imposibilidad de devenir viejas, debe considerarse como un derecho negado: la sociedad produce y construye determinados tipos 
de envejecimientos y otros no. Es la sociedad la que brinda o quita ciertas herramientas en el curso de determinadas vidas o la que otorga o quita derechos. Así, si la sociedad es artífice de nuestro devenir y anhela que envejezcamos cada vez más, debe también ser responsable del derecho que se le niega a este grupo.

\section{Reflexiones finales}

Luego de haber observado los principales hitos en las biografías de los y las mayores estudiados y de qué modo ellos habrían impactado en sus cursos de vida y adultez mayor, es momento de repasar comparativamente los modelos de vejeces estudiados

En principio debemos destacar que respecto a los mayores gays y a las lesbianas el género no parece haber interferido en sus esperanzas de vida o al menos marcando una diferenciación significativa en comparación a la media argentina. Sin embargo, si bien el género, al igual que la vejez, es una construcción social, la misma no es estática. También se construye y reconstruye en el curso de la vida. Así, a pesar de que recibimos ciertos roles asociados al género y un patrón de normas y conductas que debiéramos cumplir, como también un conjunto de estigmas ante la inobservancia de esas pautas, el mismo no opera de una vez y para siempre en nuestras vidas. Por el contrario, se va reelaborando en el curso vital. De ese modo, puede no percibirse su impacto sobre la expectativa de vida, pero no desconocerse su influjo en el modo y en la calidad en que esas biografías han sido transitadas.

Por otro lado, un dato que puso de relieve el trabajo de campo realizado fue la presencia de divergencias entre las diferentes generaciones dentro del mismo grupo de mayores. Eso se evidencia por ejemplo en la representación de las personas más jóvenes del grupo de mayores, quienes han podido experimentar el impacto de los derechos conseguidos en la última década. De esa forma, en los grupos estudiados, encontramos esperables diferencias en torno a las cosmovisiones de cada grupo etario.

Sin duda, la heterogeneidad de un grupo que se basa en una etapa de la vida iniciada a los 60 años, nos invita a una profunda reflexión sobre las diversas características que atañen a las personas que dan forma a ese vasto cohorte etario.

Así, con conceptos como los de “viejos jóvenes” (60 a 74 años) y “viejos viejos” (desde 75 años en adelante), elaborados por Neugarten (1970 y 1996), podemos entender las diferencias que existen en torno a las generaciones y los diversos marcos de socialización, los modos de ver, ser y hacer, al igual que las posibilidades e imposibilidades. Tal es el caso de 
la "salida” del armario o considerar que allí reside el horizonte deseable de todas las personas LGBT.

$\mathrm{Al}$ mismo tiempo, debe considerarse que los nuevos contextos al tiempo que otorgan un conjunto de derechos sin comparación -como el Matrimonio Igualitario o la Ley de Identidad de Género-, presentan un panorama disruptivo para los y las mayores.

Las personas gays, trans y lesbianas viejas, socializadas en otros períodos, debieron aprender e incorporar que su hacer y ser era desde la óptica estatal delictivo, para religión un pecado o patológico desde el enfoque sanitario. De ese modo, la misma cualidad de sus vidas que hasta hace años atrás los convertía en objeto de persecución estatal, médica y religiosa, hoy los ubica, por ejemplo, en el lugar de objeto de estudio y como personas entrevistables (Rada Schultze, 2018b). Por esa razón, no es casualidad que las personas entrevistadas ofrezcan cosmovisiones diversas y tengan posibilidades diferentes a las de los otros grupos de edades.

Una vez estudiadas las principales dimensiones de los cursos de vida de gays, lesbianas y trans, repasemos cuáles han sido los eventos que ellos y ellas consideran puntos de inflexión en estas trayectorias.

Estudiar lapsos temporales tan amplios como los que aquí se indagaron, analizándolos a partir de las memorias de los entrevistados y las entrevistadas, supuso encontrar cambios en sus historias de vida, al igual que dar cuenta del sentido que ellos y ellas atribuyeron a esos episodios y modificaciones en sus biografías. En esa línea debe decirse que aquí se ha trabajado con personas mayores rememorando sus eventos trascendentes en el curso de sus vidas para, mediante su reminiscencia y la reconstrucción de sus memorias y trayectorias, conocer los aspectos que ayudarán a comprender en qué medida se elaboró una vejez diferencial.

En ese sentido, uno de los principales hitos significativos para ellos y ellas ha sido el regreso de la democracia hacia finales de 1983. Si bien este cambio político tardó tiempo en convertirse en un cambio cultural -de hecho las razias y edictos policiales continuaron vigentes durante gran parte del período democrático-, fue para los y las mayores una etapa significativamente mejor que los contextos represivos de su juventud.

Los años 1980 también darían otro episodio bisagra en sus trayectorias: la aparición de la pandemia del VIH, la cual además de acabar con la vida de muchas de las personas del colectivo también trastocaría las relaciones sociales y sexuales del grupo producto del desconocimiento y temor a la epidemia. 
Tiempo después, otro evento significativo impactaría en sus biografías: el advenimiento y consolidación de un modelo socioeconómico como el neoliberal que representaría a la juventud como sinónimo del dinamismo y lo deseable en detrimento de la vejez, relacionada ahora como sinónimo de lo obsoleto. Este nuevo conjunto de reglas, al tiempo que generaba un mercado pensado para los jóvenes (Sánchez, 2002), transformaría las sociabilidades de los y las mayores. En primer lugar, la llegada de internet y el chat, pasarían a segundo plano a anteriores modos de socialización como las teteras, el yire y el juego de miradas (Langarita, 2015). Sin embargo, si bien las personas mayores pueden hacer uso de las llamadas "redes sociales” como método de socialización (como por ejemplo las aplicaciones para móviles), es sabido que estas herramientas fueron pensadas para los grupos más jóvenes, motivo por el cual los y las mayores sientan un extrañamiento ante estas y evoquen con nostalgia antiguas formas de seducción, como los encuentros “cara a cara”.

En efecto, las personas viejas presienten que su lugar de pertenencia se ha ido perdiendo, como así también ciertos privilegios y una parte de su identidad. A su vez, el tiempo en el que gestaron su identidad queda lentamente en el pasado, deviniendo en una etapa de sus vidas que ya no vuelve y que habitará en sus recuerdos. Un momento de sus vidas al que sólo acceden mediante su reminiscencia. El tiempo es un constante devenir; el continuo fluir de una arena movediza en la que no regresaremos sobre nuestros pasos más que en los recuerdos. Asimismo, tanto el pasado como el futuro son negaciones: mientras que el tiempo por venir es un “todavía no”, el tiempo pasado es un “ya no” (Simmel, 2007). A su vez, en la tarea de recuperar las propias historias y experiencias además de realizar una lectura de nuestras biografías, estamos siendo los personajes estelares, los narradores y los editores del pasado a la luz de los sucesos actuales (Ricoeur, 2006). Pero también, además de conversar con nuestro pasado en el contexto de nuestras vivencias presentes, lo interpretamos con fundamento en nuestras proyecciones y representaciones futuras en base a quiénes queremos ser.

De este modo, es comprensible que en un período de aprobación de leyes (como el Matrimonio Igualitario o la Ley de Identidad de Género) o de mayor apertura y aceptación a la heterogeneidad sexual, las personas mayores sigan alegando que "antes vivían mejor” a pesar de que desde nuestra cosmovisión actual eso pueda resultar inverosímil. A pesar de que estas personas han vivenciado episodios de dolor en sus vidas, debieron aprender a sortearlas con los elementos de la época, gestando sus identidades en esos contextos. Es entonces entendible que no estén dispuestos a negociar sus pasados $\mathrm{y}$, por consiguiente, sus 
identidades, ya que nadie querría en una sociedad edadista y homo, lesbo y transfóbica ser considerado como un viejo o vieja sufriente.

Por otro lado, aquellos años en los que fueron personajes principales, los y las forjó como una generación. Esto les brindaría la facultad de comprender y compartir códigos con otros protagonistas del mismo grupo etario, tanto del propio colectivo -los “entendidos” o personas del "ambiente", en palabras de gays y lesbianas mayores- como de la sociedad en su conjunto. El hecho de formar parte de una generación les dio la posibilidad de vincularse y compartir lenguajes, gustos, consumos, entre otros, que darían un sentido de pertenencia a una época y a un subgrupo que también tendría sus propias características del período (como por ejemplo las ya nombradas sociabilidades subterráneas). Asimismo, los consumos se metamorfosean y regeneran, pero no dejan de avanzar en dirección a los potenciales nuevos clientes. Estos virtuales consumidores serán nuevamente jóvenes protagonistas. De esta forma, las personas mayores comienzan a perder su espacio y es entendible que sientan desconfianza y desasosiego. En simultáneo, el tiempo presente se nos exhibe como una encrucijada que no ha sabido cómo dirimir históricos problemas y el futuro como un enigma. Esto conduce a que las personas deseen, al menos, proteger lo conocido e imaginar años venideros que se asemejen más a los pasados que a nuestra actualidad (Bauman, 2017).

No obstante, esta no debería ser razón para pensar que las personas mayores LGBT o los viejos y las viejas en general son retrógradas, conservadoras o no simpatizan con los cambios socioculturales. Ocurre que a los y las mayores LGBT se les presenta un nuevo marco que viene a resquebrajar todo lo conocido e incorporado en épocas pasadas. Uno de estos, tal vez donde con mayor énfasis se evidencia la diversidad generacional, es en el antagónico dúo que componen la invisibilidad (desde la visión crítica de las personas jóvenes hacia las mayores) e hipervisibilidad (desde la queja de los y las mayores hacia el grupo joven).

Es importante entonces recapitular que los grupos etarios aquí analizados han sido socializados bajo un contexto opresivo que estigmatizaba sus sexualidades (Rada Schultze, 2015). Alcanza con recordar que recién a inicio de los años 1990 la Organización Mundial de la Salud quitaría la homosexualidad de su lista de enfermedades mentales, momento de la historia en el que las personas entrevistadas ya eran adultas y habían interiorizado los valores y representaciones que la sociedad tenía sobre ellos y ellas. Hasta ese momento, las personas LGBT vivieron marcados como enfermos y estigmatizados como tales. Empero, como señalan Rada e Ingrosso, “lo que antes se consideraba una enfermedad o un trastorno, hoy es 
el tema de este artículo” (2018: 41). ${ }^{11}$ Lo que ayer aprendieron que era oprobioso, hoy las y los vuelve testigos de un período.

En esa línea, a pesar de que es cierto que no existe modo de regresar sobre aquellos pasos dados, fue el horizonte de este artículo recuperar las memorias de los viejos gays y las viejas trans y lesbianas mediante una "lectura a contrapelo”, ya que sus biografías son explicativas de su propio presente como personas mayores y también nos brindan herramientas para interpretar el presente de los y las más jóvenes, debido a que se trata de memorias de una comunidad en el contexto de la historia argentina reciente. En síntesis, se trata de memorias subyacentes que al conformar una cultura minoritaria se oponen a la historiografía y memoria oficial. De esa forma, permanecen escondidas y brotan en momentos de crisis (Pollack, 2006). Estas han sido las memorias y biografías que se persiguió rastrear y sacar a la luz a lo largo del artículo.

Por otro lado, en lo que compete a los cambios sucedidos en los últimos años, más allá del Matrimonio Igualitario y la Ley de Identidad de Género, se debe hacer mención a diferentes ampliaciones de derechos como la Unión Civil en la Ciudad de Buenos Aires en 2002, el otorgamiento de pensiones a viudos y viudas del mismo sexo por un decreto presidencial del 2008. Si bien en ellas podremos encontrar una serie de limitaciones, es acertado destacar un aspecto significativo en relación a los hitos destacados.

A pesar de que las políticas son debatibles y mejorables, han favorecido un giro en la autopercepción de las personas adultas. Así, mientras algunos años atrás los y las mayores utilizaban categorías como "amigo" o “amiga” para referirse a sus parejas, la conquista de estas leyes y derechos legitimó la historia de esas relaciones amorosas, cambiándole el significado a esos vínculos y reconociendo la pérdida y el duelo de un ser querido. Ese pasaje de la “amistad” a la “pareja” resignificó la unión de las personas y otorgó un nuevo sentido a ellos y ellas mismas.

Existe además otra instancia en donde las nociones identitarias se transformaron y fue en el modo que las personas se definían a sí mismas. De esa forma, algo que para los viejos era descriptivo e incluso identitario, ya que asignaba un rol sexual, conoció una licuación de sentido y pasó a ser una ofensa. Por ejemplo, expresiones como "puto” u "homosexual” son actualmente agravios con los que una persona gay quisiera ser llamado. A su vez, la categoría de "homosexual” retrotraía a épocas en las que se la asoció a un desorden mental.

${ }^{11}$ Traducción propia del original en italiano 
Como se vio en este artículo, las transformaciones sociales y políticas son recientes. Por ese motivo, las personas mayores homosexuales-gays y lesbianas, educados en otros contextos de la Argentina, no experimentaron (o no desean conocer) un proceso de autoreconocimiento pleno siendo empujadas al anonimato.

Por último, esbozadas las principales características de las personas mayores gays, lesbianas y trans, podemos diseñar algunos lineamientos fundamentales para pensar formas de construir un "envejecimiento exitoso". A tal fin, será nuestro trabajo en pos de una sociedad más justa y equitativa, repensar las expectativas de rol de la población anciana; un grupo etario que cada vez supondrá mayores proporciones de la población y que afronta dificultades cotidianas, consecuencia de limitaciones personales como sociales.

Dada la doble y triple discriminación vivida en los cursos de vida de las personas estudiadas en principio deberíamos procurar establecer vínculos satisfactorios basados en el mutuo respeto a los diferentes grupos etarios y las diversas etapas del ciclo vital, logrando así comprender a cada una. Ejemplo de eso ha sido el papel desempeñado por las trans “nodrizas” acogiendo a las jóvenes migrantes.

A pesar de que la vejez se nos presenta desde el sentido común como un momento estanco de la vida, eso no se condice con la idea de la adultez mayor en tanto etapa de la vida durante la cual las personas realizan un intercambio activo (social, económico, político, entre otros).

De ese modo, debido a que los intercambios entre generaciones se debilitan frente a los estereotipos que devalúan la imagen de la vejez, plantear un vínculo y conversación entre las distintas cohortes de edad permitirá a) construir nuevas pautas sociales con base en la solidaridad e interdependencia entre todos los grupos etarios y sexuales, b) crear redes de apoyo en el acompañamiento de grupos de edades y sexuales excluidos, c) dar información confiable que aporte conocimiento en la lucha contra los prejuicios y mitos que originan situaciones edadistas, homo, lesbo y transfóbicas y, d) sostener en las personas mayores el rol de transmisor cultural, papel que al mismo tiempo resignificará la propia imagen que tienen de sí. A su vez, el ejercicio reminiscente facilitará la integración entre el pasado y el presente dándole continuidad a sus vidas y reforzando así la identidad de los viejos y viejas.

De momento se ha podido observar de qué forma el género y los condicionantes sociales han impacto en el curso de vida dando lugar a tipos de vejeces diversas, entendiendo de qué modo se forja un envejecimiento diferencial en el marco de la dimensión genérico-sexual. En efecto, no fue el sexo o el género en sí mismo lo que daría origen a esas disímiles 
trayectorias, sino el influjo social; las connotaciones que tiene para la sociedad el hecho de ser parte de las llamadas minorías sexuales y cómo repercuten en sus envejecimientos.

A su vez, es en la vejez en donde la diversidad toma mayor relevancia, manifestándose la variedad de vivencias (positivas y negativas) acumuladas a lo largo del curso de la vida. De ese modo, sería imposible ceñir dicha heterogeneidad a categorías acabadas.

Por el contrario, en el transcurso de este artículo se buscó construir modos de envejecimientos de homosexuales-gays, lesbianas y trans que sirvieran para conocer y comparar sus principales características, sin dejar de lado las particularidades que los y las diferencien, ya que lo inestimable de un estudio centrado en los cursos de vida es dar cuenta de esa diversidad.

Así fue que en estas líneas se persiguió comprender y aprehender esa heterogeneidad en un vasto sentido recobrando las memorias de los y las protagonistas -muchas veces excluidos del propio colectivo por motivos etarios, genérico-sexuales o económicos- sin partir previamente con categorías monolíticas de análisis, sino procurando que brotaran de sus propios testimonios.

\section{Bibliografía}

AGAMBEN, Giorgio (1998): Quel che resta di Auschwitz. L'archivio e il testimone, Torino, Bollati Boringhieri Editore.

ALBARRACÍN, Matilde (2008) "Libreras y tebeos: las voces de las lesbianas mayores", en R. Platero (Coord): Lesbianas. Discursos y representaciones, España, Melusina.

BARRETT, Donald y POLLACK, Lance (2005): "Whose gay community? Social class, sexual self-expression, and gay community involvement", en The Sociological Quarterly 46, issue 3, pp. 437-456.

BAUMAN, Zygmunt (2005): Legisladores e intérpretes. Sobre la modernidad, la posmodernidad y los intelectuales, Buenos Aires, Universidad de Quilmes.

BAUMAN, Zygmunt (2017): Retrotopía, Buenos Aires, Paidós.

BECKER, Howard (2009): Los extraños. Sociología de la desviación, Buenos Aires, Siglo XXI.

BERKINS, Lohana y FERNÁNDEZ, Josefina (coords) (2005): La gesta del nombre propio. Informe sobre la situación de la comunidad travesti en la Argentina, Buenos Aires: Ediciones Madres de Plaza de Mayo 
BERKINS, Lohana (comp) (2007): Cumbia, copeteo y lágrimas. Informe Nacional sobre la situación de las travestis, transexuales y transgéneros, Asociación de la lucha por la Identidad Travesti, Transexual

CAVALLI, Stefano (2007). "Modèle de parcours de vie et individualisation: un état du débat”, en Gérontologie et Société, 123, 55-69.

DURKHEIM, Emile (2005): Las reglas del método sociológico, Madrid, Biblioteca Nueva.

ELDER, Glen (1998): “The life course and human development”, en R. M. Lerner (Ed.):

Handbook of child psychology. Volume 1: Theoretical models of human development, New York, Wiley \& Sons, pp. 939-991.

ERIBON, D (2006): Reflexiones sobre la cuestión gay, Barcelona, Anagrama

ESTES, Carroll y BINNEY, Elizabeth (1989): “The Biomedicalization of Aging. Dangers and Dilemmas”, en The Gerontologist, Vol. 29, nro. 5, pp. 587-596.

GOFFMAN, Erving (2010): Estigma. La identidad deteriorada, Buenos Aires, Amorrortu.

LALIVE D'EPINAY, Christian; BICKEL, Jean-François; CAVALLI, Stefano y SPINI, Dario (2005): “Le parcours de vie: émergence d'un paradigme interdisciplinaire”, en J. F. Guillaume (Ed.), Regards croisés sur la construction des biographies contemporaines, Liège: Les Editions de l'Université de Liège, pp. 187-210.

LALIVE D'EPINAY, Christian y CAVALLI, Stefano (2007): “Changements et tournants dans la seconde moitié de la vie”, en Gérontologie et Société, 121, 45-60.

LANGARITA, José (2015): En tu árbol o en el mío. Una aproximación etnográfica del sexo anónimo entre hombres, Barcelona, Bellaterra.

LEVY, Becca y BANAJI, Mahzarin (2002) “Implicit ageism” en T. D. Nelson (comp.): Ageism. Stereotyping and prejudice against older persons, Massachusetts: The Mit Press, pp. 49-75

MAGNUS, George (2011): La era del envejecimiento, México, Editorial Océano.

NEUGARTEN, Bernice (1970): "Dynamics of transition of middle age to old age. Adaptation and the life cycle”, Journal of Geriatric Psychiatry, IV,1, New York, 71-100.

NEUGARTEN, Bernice (1996): Los significados de las edades, Barcelona: Herder.

MECCIA, Ernesto. (2011): Los últimos homosexuales, Buenos Aires, Gran Aldea.

MERTON, Robert (1968): Teoría y Estructura Sociales, México, Fondo de Cultura Económica. 
ODDONE, Julieta y AGUIRRE, Mónica (2005): “Impacto de la diversidad en el envejecimiento”, en PsicoLogos: Revista de Psicología, Universidad de Tucumán, Año XIV $\mathrm{N}^{\circ}$ 15, Pp. 49-66.

PECHENY, Mario (2005) “Identidades discretas” en L. Arfuch (comp.) Identidades, sujetos y subjetividades. Buenos Aires: Prometeo, pp. 131-153.

PELLISSIER, Jérôme (2013): “¿A qué edad se es viejo?” en Le Monde Diplomatique, Año XIV, No 168 , pp. 22-24.

POLLAK, Michael (2006): Memoria, olvido y silencio. La producción social de identidades frente a situaciones límites. Buenos Aires, Ediciones Al Margen

RADA SCHULTZE, Fernando (2012): "Sociabilidades homosexuales puestas en perspectiva. Una mirada sobre el desarrollo de los modos de ser y hacer gay", en Sudamérica Revista de Ciencias Sociales, Vol. 1 Nro 1, pp 71-96.

RADA SCHULTZE, Fernando (2014): "El movimiento político de lesbianas, gays, transexuales y bisexuales argentino y su participación en las políticas estatales. Cambios y continuidades en sus demandas, estrategias y memoria colectiva desde sus orígenes a la actualidad”, tesis de Maestría en Políticas Sociales, Universidad de Buenos Aires.

RADA SCHULTZE, Fernando (2015): "Los derechos sexuales en la agenda de las políticas públicas. Aportes para la reflexión”, Revista Argumentos, Vol. 9, pp. 12-18.

RADA SCHULTZE, Fernando (2016a): “El Paradigma del Curso de la Vida y el método biográfico en la investigación social sobre envejecimiento”, en Revista de Investigación Interdisciplinaria en Métodos Experimentales, Buenos Aires, pp.83-110

RADA SCHULTZE, Fernando (2016b): "Situación laboral y condiciones de trabajo de las travestis en el Área Metropolitana de Buenos Aires”, en Red Sociales, Universidad de Luján, Vol. 4, Nro. 1, pp. 67-90

RADA SCHULTZE, Fernando (2018a): “Trayectorias y memorias de los y las mayores LGBT argentinos”, en C. E Henning y C. Braz (Orgs): Gênero, sexualidade e curso da vida: Diálogos latino-americanos, Editora Imprensa Universitária, Universidade Federal de Goiás, pp. 111-143.

RADA SCHULTZE, Fernando (2018b): La diversidad en el curso de la vida. Cambios y continuidades en el envejecimiento de gays, lesbianas y trans, Buenos Aires, Teseo.

RADA SCHULTZE, Fernando (2018c): “La diversidad en el curso de la vida. Modos de envejecer de gays, lesbianas y trans”, en Revista Ciencias Sociales, № 95, pp. 54-63. 
RADA SCHULTZE, Fernando e INGROSSO, Matteo (2018): "Le coppie lesbiche e gay in Argentina. Riflessioni sull'amore, la famiglia e la sessualità nella terza età omosessuale”, en AG About Gender - Rivista internazionale di studi di genere, Vol. 7, N 14, pp. 22-46.

RAPISARDI, Flavio y MODARELLI, Alejandro (2001): Fiestas, baños y exilios. Los gays porteños en la última dictadura militar. Buenos Aires, Sudamericana.

RAUP, Jana y Myers, Jane (1989): “The empty nest syndrome: myth or reality?”, Journal of Counseling \& Development, 68 (2), pp. 180-183.

RICOEUR, Paul (2006): Tiempo y narración. Volumen III. El tiempo narrado, Buenos Aires, Siglo XXI.

SÁNCHEZ, Carlos (2002): “Minorías sexuales y participación política”, en F. Vidal y C. Donoso (eds): Cuerpo y sexualidad, Santiago de Chile, FLACSO, pp. 113-117.

SCHWARZ, Patricia (2008): “Las lesbianas frente al dilema de la maternidad”, en M. Pecheny, C, Figari y D. Jones (comp) (2008): Todo sexo es político, Buenos Aires, Libros del Zorzal. pp. 193-214

TARROW, Sidney (1997): El poder en movimiento. Los movimientos sociales, la acción colectiva y la política, Madrid, Alianza.

YUNI, José; URBANO, Claudio y ARCE, María del Carmen (2003): Discursos sociales sobre el cuerpo, la estética y el envejecimiento, Córdoba, Editorial Brujas.

WITTGENSTEIN, Ludwig (2007): Aforismos. Cultura y valor, Madrid, Espasa Calpe.

Recebido 23/04/2019

Aprovado 28/05/2019 